\title{
The Frequency of Malignancy in Nodular Thyroid Disease
}

\author{
Hussein Jasim Dadoosh AL-janabi, M.B.Ch.B. D.S \\ General surgeon at Al-Nuaman Teaching Hospital \\ Basam Kamal Samad, M.B.Ch.B. D.M \\ A specialist physician at Al-Nuaman Teaching Hospital \\ Qusay Sami Ahmed, M.B.ch.B. PGDIP Audiology \\ Al-Nuaman Teaching Hospital
}

\begin{abstract}
The thyroid nodules occur quite frequent but, thyroid carcinoma is a relatively infrequent malignancy. Thyroid carcinoma is generally regarded as a condition of modest oncologic importance because it accounts for less than $0.5 \%$ of cancer deaths (less than $2 \%$ of all cancers). A sample of 196 patients with nodular thyroid enlargements who underwent thyroidectomies were included in this cross-sectional study. The diagnosis of thyroid carcinoma was confirmed in 18(9.2\%) patients in this series. Most of the patients were presented with benign goiters, mainly nontoxic multinodular goiter. Cervical lymphadenopathy was present in $4(22.2 \%)$ at presentation. In ten patients out of the 18 patients $(55.5 \%)$ diagnosed with carcinoma, it was possible to make a correct diagnosis of thyroid carcinoma before and at operation time. While in the remaining eight patients $(44.5 \%)$ the diagnosis of carcinoma was made at a histopathological examination of the surgical specimens. In conclusion goiter affect female more than male. Nodular colloid goiter was the main pathology. Thyroid carcinoma reported in $9.18 \%$ of the sample with goiters. Papillary carcinoma was the commonest histopathological type among patients with carcinomas.
\end{abstract}

Keywords: Goiter, multinodular goiter, carcinoma, ANF

DOI: $10.7176 / \mathrm{JHMN} / 66-04$

Publication date:September $30^{\text {th }} 2019$

\section{Introduction}

Thyroid carcinoma is generally regarded as a condition of modest oncologic importance because it accounts for less than $0.5 \%$ of cancer deaths ${ }^{(1)}$, this reflects the combination of its low frequency of occurrence (less than $2 \%$ of all cancers $)^{(1,2)}$. It carries good prognosis, 5 years survival rate exceeding $(90 \%)^{(3)}$. Thyroid cancer is accounts for more than $90 \%$ of all endocrine cancers ${ }^{(4)}$.

In Iraq for the years 1989-1991, thyroid carcinoma constituted 3.5\% of all malignancies in Iraqi females and $1.3 \%$ of male's malignancies during $1994^{(5)}$, in 1945 Cole $^{(6)}$ showed that a high percentage $(17 \%)$ of nontoxic nodular goiters being malignant, and (24\%) of single nodule. In 1948, Lockwood ${ }^{(7)}$ recommended the removal of every nodular gland, as well recommended Beahr's et al ${ }^{(8)}$. Thus an aggressive surgical approach to the thyroid nodules started soon after its finding is necessary to permit control of cancer at its early stage. This was supported by Sokal ${ }^{(9)}$ and Crile ${ }^{(10)}$ study.

This study focused a concern primarily on the frequency of thyroid carcinoma in the general surgical practice among large number of patients with goiters. Also the relationship of malignancy to these goiters, beside the carcinoma that clinically presented and managed as apparently benign goiter.

\section{Patients and methods}

A total of 196 patients presented with goiters, for whom thyroidectomies were done at Al-Kadhimiah Hospital during the period from January 2000 to Aug 2002, were included in the study. The indications for operation were: symptoms of compression from enlarged dominant nodule that did not involute with L-thyroxin suppression; patient's wishes for cosmetic reasons; and suspicious cytological findings of fine needle aspiration.

For each case a special form was filled by data including the hospital record number, name, age, sex and residence of the patient. Data derived from the medical file record. All the available information about the presenting symptoms and the past history was obtained. Physical examination was performed with attention to any suggestive signs of malignancy in the thyroid gland. Shape and symmetry of the goiter (diffuse, multinodular, or single nodule) and presence of cervical lymph nodes enlargement. Thyroid function tests, radioisotope of the thyroid gland, and thyroid ultrasonography was done for all of the patients. Percutaneous fine needle aspiration cytology (FNA) was done for most of the patients. The pathologists report of FNA was in 4 categories: (benign lesion, malignant lesion, Suspicious for malignancy), the latter was regarded as a malignant report.

\section{Statistical analysis}

Data were collected grouped and tabulated, the results expressed by frequencies and percentages. 


\section{Results}

Table- 1 showed the age and sex of the patients participated in the study. Female constitute $67.3 \%$ with a ratio to male of 2.06:1. Majority of patients $41.3 \%$ were in the age group of $30-39$ years, and only $2 \%$ were in the age group of 60 years and above.

Table 1: Age and sex of the patients

\begin{tabular}{|l|c|c|c|c|}
\hline Age range (years) & Female & Male & Total & $\%$ \\
\hline $19-29$ & 55 & 25 & 80 & 40.8 \\
\hline $30-39$ & 55 & 26 & 81 & 41.3 \\
\hline $40-49$ & 14 & 6 & 20 & 10.2 \\
\hline $50-59$ & 7 & 4 & 11 & 5.6 \\
\hline $60-79$ & 1 & 3 & 4 & 2.0 \\
\hline Total & $132(67.3)$ & $64(32.7)$ & 196 & 100 \\
\hline
\end{tabular}

The diagnosis of thyroid carcinoma was confirmed in 18 patients in this series. Most of the patients were presented with benign goiters, mainly nontoxic multinodular goiter. In ten patients out of the 18 patients $(55.5 \%)$ diagnosis of thyroid carcinoma was made before and at operation time. While in the remaining eight patients $(44.5 \%)$ the diagnosis of carcinoma was made at a histopathological examination of the surgical specimens after they had been treated as " apparently " benign goiters (Figure-1).

\section{$\square$ Diagnosis prior or on operation time \\ Diagnosis on histopathology}
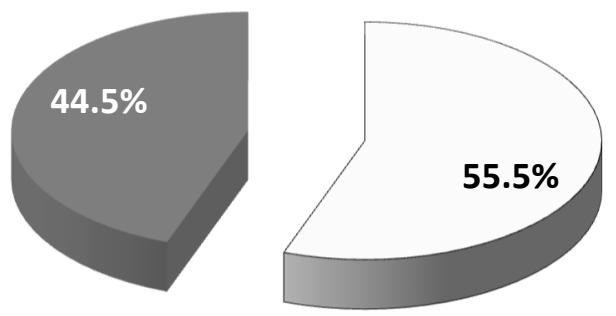

Figure 1: Time of diagnosis of malignancy

Table-2 showed that patients with asymptomatic goiter constituted $38.9 \%$ of total patients with thyroid carcinoma. Cervical lymphadenopathy found in $4(22.3 \%)$ patients at presentation time. Less mode of presentation was dyspnea (16.7\%), dysphagia (11.1\%), stridor (5.5\%), and altered voice $(5.5 \%)$.

Initially all of the 18 patients with thyroid carcinoma presented with evident disease in the neck (thyroid enlargements only in 14(77.8\%) patients, thyroid enlargement associated with cervical lymph node enlargement in $3(16.7 \%)$ patients, and one patient $(5.5 \%)$ presented with solitary enlarged cervical lymph node).

Table 2: presinting symptoms of the patients with thyroid carcinoma and their main clinical findings

\begin{tabular}{|l|c|c|}
\hline Symptoms and clinical findings at presentation & $\mathrm{n}$ & $\%$ \\
\hline Symptom at presentation & 7 & 38.9 \\
\hline Asymptomatic goiter & 4 & 22.3 \\
\hline Cervical lymphadenopathy & 3 & 16.7 \\
\hline Dyspnea & 2 & 11.1 \\
\hline Dysphagia & 1 & 5.5 \\
\hline Stridor & 1 & 5.5 \\
\hline Altered voice & 14 & 77.8 \\
\hline Clinical findings at presentation & 3 & 16.7 \\
\hline Thyroid enlargement & 1 & 5.5 \\
\hline
\end{tabular}

Table-3 represented the results of investigations done and the surgical notes. All patients with thyroid carcinoma tested by thyroid function test and were found to be euthyroid. Thyroid isotope scan was done for the majority of patients, it showed multiple hypo functioning areas in $41(26.3 \%)$ patients and single cold nodule in $10(6.4 \%)$ patients. Thyroid ultrasonography revealed multiple complex masses in $6(\%)$ patients, single solid mass in $2(\%)$ cases and single cystic lesion in $8(\%)$ patients . 
Chest X-ray showed that four patient had retrosternal extension of the goiter. FNA done for 40 patients, 15 of them the aspirate was reported by the pathologist to be inconclusive, the final diagnoses for them were positive. There were no false positive results.

One patient with carcinoma, the diagnosis was made by cervical lymph node biopsy. Operative findings reported invasion of extra thyroidal cervical tissues in three patients.

Table 3: Main investigations done for the diagnosis and evaluation of patients

\begin{tabular}{|c|c|c|c|}
\hline Investigations & Results & patients & $\%$ \\
\hline $\begin{array}{l}\text { Thyroid function test for those with thyroid carcinoma } \\
(\mathrm{n}=18)\end{array}$ & Euthyroid & 18 & 100 \\
\hline \multicolumn{4}{|l|}{ Thyroid isotope scan $(n=156)$} \\
\hline & Multiple hypo-functioning area & 41 & 26.3 \\
\hline & Single cold nodule & 10 & 6.4 \\
\hline & Negative isotope scan & 105 & 67.3 \\
\hline \multicolumn{4}{|l|}{ Thyroid ultrasound study $(\mathrm{n}=196)$} \\
\hline & Multiple complex mass & 6 & 3.1 \\
\hline & Single solid mass & 2 & 2.0 \\
\hline & Single cystic mass & 8 & 4.1 \\
\hline \multicolumn{4}{|l|}{ FNA cytology $(n=40)$} \\
\hline & Malignant & 6 & 15.0 \\
\hline & suspicious & 15 & 37.5 \\
\hline & Benign & 19 & 47.5 \\
\hline Operative findings & $\begin{array}{l}\text { extra thyroidal cervical tissues } \\
\text { invasion }\end{array}$ & 3 & \\
\hline Chest x-ray & retrosternal extension of the goiter & 4 & \\
\hline
\end{tabular}

Figure-2 gave a cellular histopathology finding of the patients with carcinoma. The commonest histological type was the papillary type $12(66.7 \%)$ and 3(16.6\%) were of follicular type. The undifferentiated (anaplastic) carcinoma diagnosed in 2 cases $(11.2 \%)$ and medullary carcinoma was the diagnosis in one patient $(5.5 \%)$ only.

$66.7 \%$

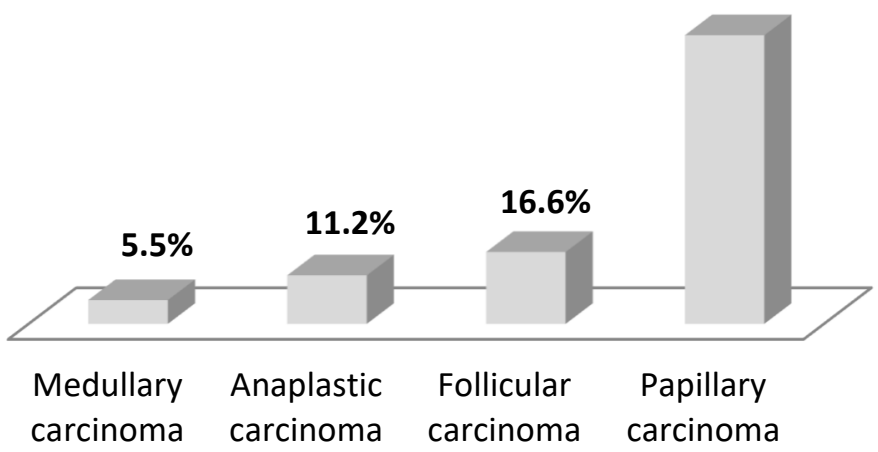

Figure 2: Rate of occurance of differenthistopathology of the 18 reported patients

\section{Discussion}

Iraq, is an endemic goiter country, the condition; partially at least is due to lack of iodine in food and water ${ }^{(11,12)}$. The iodine content of the water from Tigris river in the affected area is low ${ }^{(10)}$.

Multinodular goiter is the commonest clinical type seen in our study. This is in agreement with Shukri study ${ }^{(13)}$. Nodular colloid goiter constituted $71.4 \%$ of all thyroid pathologies in our study . A close finding had been shown by AI-Saleem \& AI-Ashbal (1973) ${ }^{(14)}$ whereby nodular colloid goiter constituted $64 \%$ of their series of thyroid pathology. There was no history of previous exposure to upper body irradiation in any of our carcinoma patients. The overall operative incidence of thyroid carcinoma was $9.18 \%$, in a similar study in Italy, which is also an endemic goitrous area ${ }^{(15)}$, Ardito et al. ${ }^{(16)}$ found that the frequency of thyroid carcinoma in surgically treated thyroid diseases is $6 \%$. In USA, Colcock \& $\mathrm{King}^{(17)}$ found that carcinoma of the thyroid constituted $6.4 \%$ of thyroid pathologies in their series, thyroid carcinoma was the third common pathology affecting the thyroid in this study which represents $9.18 \%$. Belfiore et al. ${ }^{(18)}$ reported a lower incidence in his study in 1992 as he found an overall thyroid cancer was $4.6 \%$ among their series of 5637 patients with nodular goiters.

Ultrasonography is useful in determining the size of the nodule and whether it is single or multinodular thyroid disease, but it cannot detect thyroid cancer ${ }^{(19)}$. Fine needle aspiration biopsy is currently the procedure of choice 
for evaluating all thyroid nodules ${ }^{(20)}$, the sensitivity of FNA in our study was $(85.8 \%)$, the specificity was $(100 \%)$ and the accuracy was (90\%), these figures are comparable to those of Gharib and Goellner study who report an overall result as sensitivity of $83 \%$ and a specificity of $92 \%$ translates into a diagnostic accuracy greater than $95 \%{ }^{(21)}$. The procedure is safe, with negligible risk of cancer dissemination, Expansion in application FNA test may permit more appropriate surgical procedures.

In the current study the frequency of carcinoma in males with single thyroid nodule was $(29.4 \%)$ which was higher than that found in females with single nodules $(5.2 \%)$. In spite of larger frequency of females among the study sample. This high risk of malignancy among males presenting with single thyroid nodules was similar to the findings shown by other series of studies ${ }^{(13,18,20)}$.

\section{Conclusion}

The majority of the patients with goiter in our study were in the age group (30-39) years. Female affected more than male. Nodular colloid goiter was the highest pathology. Thyroid carcinoma was reported in $9.18 \%$ of the sample with goiters. Papillary carcinoma was the commonest histopathological type $(66.6 \%)$ among patients with carcinomas.

Conflict of interest: We declare that there was no conflict of interest

\section{References}

1. Akseln, L.A., Hakdirseb, T., Thoresen, S.O., Glattre, E. (1991). Survival and causes of death in thyroid cancer: a population based study of 2479 CQ, Norway Cancer Research, 51, 1234-41.

2. Pelizzo, M.R., Toniato, A., Piotto, A., Bernante, P. (1994). Epidemiolooy and risk factors in thyroid carcinoma. Chir - Italy, 46, 1-3.

3. Vassilopoulou-Sellin, R. (1995). Management of papillary thyroid cancer, Oncology, 9, 145-52.

4. Robbins, J., Merino, M.J., Bioce, J.D., Ron, E., Alexander, H.R., Norton, J.A., Reynolds, J. (1991). Thyroid cancer: A lethal endocrine neoplasm. Ann. Intern Med, 115 (2), 133-47.

5. Ministry of Health (MOH). (1996). Iraqi cancer Board, registry Baghdad, 1992-1994.

6. Cole, W.H., Slaughter, D.P., Rossiter, L.H. (1945). Potential dangers of nontoxic nodular goiter. JAMA, 127, 883-88.

7. Lockwood, A.L. (1948). Certain goiter problems. J Clin Endocrinol, 8, 776.

8. Beahrs, O.H., Pemberton, J., and Black, B.M. (1951). Nodular goiter and malignant lesions of the thyroid gland, $J$ Clin Endocrinol Metab, 11, 1157-65

9. Sloan, L.W. (1954). Of origin, characteristics, and behavior of thyroid cancer. J Clin Endocrinol Metab, 14, 1309-35.

10. Crile, G. (1959). Thyroid nodules and the fallacy of "all or none" teaching. JAMA, 170(4), 470-71.

11. Caughey, J.E., and Follis, R.H. (1965). Endemic goiter and iodine malnutrition in Iraq. Lancet, 1, 1032-34.

12. Demarchi, M., AI-Hindawi, A., Abdul-Nabi, M., and Tajeldin, H. (1969). Prevalence and etiology of goiter in Iraq. Am J Nut, 22, 1660-66B.

13. Shukri, A.M. (1967). The solitary thyroid nodule in Iraq. Brit J Clin Pract, 21, 75-80.

14. AI-Saleem, T., and AI-Ashbal, A. (1973). Surgical pathology of the thyroid gland in Iraq. Internal Surg, 58, 623-24.

15. Kelly, F.C., and Snedden, W.W. (1958). Prevalence and distribution of endemic goiter. Bull-WHO, 18(1-2), 5-173.

16. Ardito, G., Covallaro, A., Man+ovani, M., Pugno, V., Ceviati, F., Barbarino, A. (1982). Occult carcinoma of the thyroid. In: Coil JJ. Surg. Edin, 27, 219-23.

17. Colcock, B.P., and King, M.L. (1962). The mortality and morbidity of thyroid surgery. Surg Gyne Obst, 114, 131-36.

18. BelRore, A., La-Rosa, G.L., La-Porta, G.A., Giuffrida-Milazzo, G., Lupo, L, Regalbuto, C., Vingen, R. (1992). Cancer risk in patients with cold thyroid nodules; Relevance of iodine intake, sex, age, and multinodularity; Am J Med, 93(4), 363-69.

19. Dorsch, T.R., (1991). Evaluation of thyroid nodules. Seminars Surg Oncol, 7(2), 64-66.

20. Caruso, D., Mazzaferri, E.L., (1991). Fine needle aspiration biopsy in the management of thyroid nodules. Endocrinologist, 1, 194-02.

21. Gharib, H., and Goellner, J.R. (1993) Fine-Needle Aspiration Biopsy of the Thyroid: An Appraisal. Annals of Internal Medicine, 118, 282-89.

22. Sokal, J.E. (1959). The problem of malignancy in nodular goiter - recapitulation and challenge. JAMA, 170(4), 405-12. 